\title{
Evodiamine Inhibits the Proliferation of BGC-823 and SGC-7901 Cells by Inducing Cell Cycle Arrest and Apoptosis in Gastric Cancer
}

\author{
Hanni Zhang1, Yunliang Guo1, Keli Ge ${ }^{1 *}$, Yanan Wang1,2* \\ ${ }^{1}$ The Center for Integrated Traditional Chinese and Western Medicine, Department of Medicine, \\ Qingdao University, Qingdao, China \\ ${ }^{2}$ The Affiliated Hospital of Qingdao University, Qingdao, China \\ Email: 18942927720@163.com, *yananbb@126.com, *ntfadu@163.com
}

How to cite this paper: Zhang, H.N., Guo, Y.L., Ge, K.L. and Wang, Y.N. (2019) Evodiamine Inhibits the Proliferation of BGC-823 and SGC-7901 Cells by Inducing Cell Cycle Arrest and Apoptosis in Gastric Cancer. Open Access Library Journal, 6: e5217.

https://doi.org/10.4236/oalib.1105217

Received: January 30, 2019

Accepted: February 24, 2019

Published: February 27, 2019

Copyright $\odot 2019$ by author(s) and Open Access Library Inc.

This work is licensed under the Creative Commons Attribution International License (CC BY 4.0).

http://creativecommons.org/licenses/by/4.0/

\begin{abstract}
Gastric cancer represents a major cause of cancer-related death worldwide. Although various tactics and anti-tumor drugs have been used to improve curative effects, five-year survival rate of lung cancer patients remains poor. Evodiamine, a sophora alkaloid, has been demonstrated to exert antitumor effects on many types of cancer. However, the molecular mechanism of evodiamine against gastric cancer has not been clearly elucidated. In this study, we investigated the anti-tumor activity and the underlying mechanisms of EVO on gastric cancer cells, and found that it significantly inhibited the proliferation of BGC-823 and SGC-7901 cells by inducing cell cycle arrest at G2/M phase and cell apoptosis in a dose- and time-dependent manner. Its molecular mechanism may be that it reduces the expression of cell cyclepromoting protein $\mathrm{Cdc} 25 \mathrm{C}$ and promotes the expression of cell cycle inhibitor p53, as well as prompts the activity of caspases pathways, such as the expression level of cleaved caspase- 3 and cleaved caspase-8; cleaved caspase- 9 and cleaved PARP-1 are up-regulated, treated with EVO $(10 \mu \mathrm{M})$ at different points in time $(0,3,6,9,12,24 \mathrm{~h})$. Collectively, our data demonstrated that EVO was a potential anti-tumor agent against gastric cancer.
\end{abstract}

\section{Subject Areas}

Gastroenterology, Hepatology

\section{Keywords}

Evodiamine (EVO), BGC-823 Cells, SGC-7901 Cells, Proliferation, Cell Cycle, Cell Apoptosis 


\section{Introduction}

Gastric cancer is one of the most commonly digestive system carcinoma and remains the major cause of cancer-related death with characteristics of rapid progression, poor curative effect, easy metastasis, and unfavorable prognosis in the domestic and overseas. According to reports, the global incidence and the mortality rate of gastric cancer respectively rank fifth and third in clinical diagnosed malignant tumors [1]. In China, it has been ranking from the second among all cancers with $15.8 \%$ annual incidence ratio and $17.6 \%$ mortality ratio [2]. At present, the major treatment methods for gastric cancer mainly remain surgical resection, chemotherapy and targeted therapy, even though new treatment approaches are emerging [3]. Therefore, to search for safer and more effective therapy is an urgent problem in the treatment of gastric cancer.

Evodiamine (EVO) $\left(\mathrm{C}_{19} \mathrm{H}_{17} \mathrm{~N}_{3} \mathrm{O}\right)$ is one of the main active components in dried roots and ripe fruits of Evodia rutaecarpa, which has a wide range of pharmacological effects and has few obviously side effects or toxicity [4] (Figure 1). Recently, it has been extensively studied for its chemopreventive potential against various cancers, for instance, hepatocellular carcinoma [5] [6], breast cancer [7], colon cancer [8], lung cancer [9], prostatic cancer [10] and osteosarcoma [11]. The data have certificated that EVO exerts its anticancer activities through inhibiting cancer cell proliferation, accelerating apoptosis, inducing cell cycle arrest, suppressing invasion and metastasis, and reducing chemotherapy-induced toxicity [12]. The related research has shown that evodiamine has inhibited the effective proliferation of gastric cancer in SGC-7901 cells [13], but its specific anti-tumor molecular mechanism is still unclear. In this study, we examined the mechanism of anti-tumor effects of EVO in BGC-823 and SGC-7901 cells, finding that it exerted its anti-proliferation effects by inducing cell cycle arrest at G2/M phase and cell apoptosis in gastric cancer cells, and tried to clarify its associated molecular mechanisms.

\section{Materials \& Methods}

\subsection{Cell lines and Culture}

The Human gastric cancer cell lines (BGC-823, SGC-7901) were purchased from the National Cell Resource Center (Beijing, China). All cell lines were propagated in DME/F-12 Medium (HyClone, USA), supplemented with 10\% fetal bovine serum (FBS, Gibco, USA), $100 \mathrm{U} / \mathrm{ml}$ penicillin and $100 \mathrm{mg} / \mathrm{ml}$ streptomycin (HyClone, USA) in a humidified atmosphere with $5 \% \mathrm{CO}_{2}$ at $37^{\circ} \mathrm{C}$. The cells with $80 \%$ confluence were treated by EVO (National Vaccine and Serum Institute, Beijing, China) of different concentrations.

\subsection{Cell Viability Assay}

The Cells were seeded into 96-well plates at a density of 3000 cells/well overnight to allow their adhesion to the plate, then treated with EVO at different concentrations $(0,5 \mu \mathrm{M}, 7.5 \mu \mathrm{M} 10 \mu \mathrm{M}, 12.5 \mu \mathrm{M}, 15 \mu \mathrm{M})$ for $24 \mathrm{~h}, 48 \mathrm{~h}$, and $72 \mathrm{~h}$, 


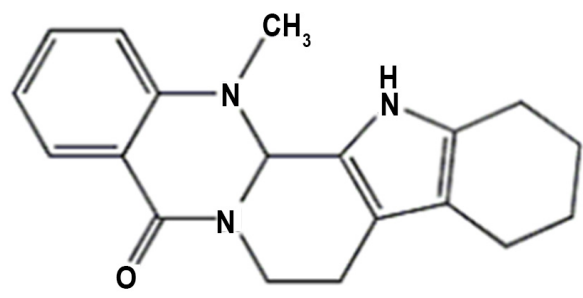

Figure 1. Chemical structures of evodiamine and its molecular formula $\left(\mathrm{C}_{19} \mathrm{H}_{17} \mathrm{~N}_{3} \mathrm{O}\right)$.

respectively. Five parallel wells for each concentration. At each time point, Cell Counting Kit 8 (CCK-8) agent (Dojindo, Japan) was added to each well and incubated at $37^{\circ} \mathrm{C}$ for $2 \mathrm{~h}$. The numbers of viable cell were calculated by detecting the optical density (OD) at $450 \mathrm{~nm}$ using the microplate autoreader (Bio-Rad, $\mathrm{CA}$, USA). $\mathrm{IC}_{50}$ was determined using the trimmed Spearman-Karber method. Cell viability $(\%)=\mathrm{OD}_{\text {treated }} / \mathrm{OD}_{\text {control }} \times 100$.

\subsection{Cell Morphology Observation}

The Cells were seeded into 6-well plates at a density of $3 \times 10^{5}$ cells/well overnight. Then, allowing their adhesion to the plate, the cells were treated with EVO $(10 \mu \mathrm{M})$ for $48 \mathrm{~h}$. The morphological changes of the cells were observed under a microscope.

\subsection{Cell Colony Formation Assay}

The cells were seeded at 500 cells/well in 6-well plates overnight, and then treated with EVO (the concentrations: $10 \mu \mathrm{M}$ ) for 5 days. Discarding the supernatant, in every well fixed with $4 \%$ paraformaldehyde for 20 minutes and stained with $0.1 \%$ Giemsa for 15 minutes at room temperature. The numbers of colony were scanned and counted with the microscope. The colony formation rate that colonies contained more than 50 cells was calculated according to the following equation "Colony formation rate $(\%)=$ (colony counts/number of seeded cells) $\times 100 \%$ ".

\subsection{Cell Cycle Analysis}

The cell cycle was detected by using flow cytometry (FCM) with propidium iodide (PI)/RNase staining solution (BD Biosciences, San Jose, CA, United States). Cells were seeded in 6-well plates at $3 \times 10^{5}$ cells per well and treated with EVO (the concentrations: $10 \mu \mathrm{M}$ ) for $48 \mathrm{~h}$. Following by collecting cells, fixed in ice-cold $70 \%$ ethanol at $4^{\circ} \mathrm{C}$ overnight in darkness. Then washed with cold PBS for two times, and added with $100 \mu \mathrm{L}$ RnaseA for $30 \mathrm{~min}$ at $37^{\circ} \mathrm{C}$, the cells were suspended in PI Staining Buffer at $4^{\circ} \mathrm{C}$ for $20 \mathrm{~min}$, finally analyzed on a flow cytometer (Becton Dickinson, Franklin Lakes, NJ, USA).

\subsection{Annexin V-FITC/PI Staining}

The apoptotic rate of BGC-823 and SGC-7901 cells were quantified with An- 
nexin V-FITC/PI double staining solution (BD Biosciences, San Jose, CA, United States) by FCM. Cells were planted into 6 -well plates at $3 \times 10^{5}$ cells per well and treated with EVO $(10 \mu \mathrm{M})$ for $48 \mathrm{~h}$. Then digested by trypsinization, washed with cold PBS for two times, and fixed cell suspension with $1 \times$ Binding Buffer. The cells were then stained with Annexin V-FITC/PI according to the manufacturer's instruction. After incubation for $10 \mathrm{~min}$ at room temperature in darkness, the apoptotic cells were detected with flow cytometry.

\subsection{Western Blot Analysis}

The cells were planted into T25 flask at $5 \times 10^{5}$ cells per flask and treated with EVO $(10 \mu \mathrm{M})$ for $48 \mathrm{~h}$, washed twice with PBS and then lysed with $300 \mu \mathrm{L}$ of RIPA buffer for $30 \mathrm{~min}$ in ice. After centrifuged at 12,500 rpm for $20 \mathrm{~min}$ at $4^{\circ} \mathrm{C}$, the supernatants were transferred to clean microcentrifuge tubes. The total protein concentration was determined using the bicinchoninic acid (BCA) (Beyotime, China) method. Equal amount of protein $(30 \mu \mathrm{g})$ from each sample was separated by $10 \%$ or $12 \%$ SDS-PAGE and transferred onto PVDF membranes. After being blocked in defatted milk (5\% in Tris-buffered saline with Tween-20 buffer) at $37^{\circ} \mathrm{C}$ for $1 \mathrm{~h}$, the membrane was incubated with various primary antibodies overnight at $4^{\circ} \mathrm{C}$ and then with appropriate secondary antibodies for $1 \mathrm{~h}$ at room temperature. After each incubation period, the membrane was washed three times with TBST (Tris buffered saline with Tween-20). Signals were visualized by ECL detection reagents (Bio-Rad, CA, USA). The protein quantitative analysis was conducted by using the Image J software.

\subsection{Statistical Analysis}

Data are presented as the mean $\pm S D$, every experiment was performed at least 3 times. The difference between the groups was assessed using a one-way analysis of variance (ANOVA) or student's t-examination by the SPSS 22.0 software. A $P$-value of less than 0.05 indicates a statistical significance.

\section{Results and Discussion}

\subsection{EVo Can Significantly Inhibit the Proliferation of Human Gastric Cancer Cells}

The proliferation activity of the gastric cancer cells, which were treated with EVO at different concentration $(0,5 \mu \mathrm{M}, 7.5 \mu \mathrm{M} 10 \mu \mathrm{M}, 12.5 \mu \mathrm{M}, 15 \mu \mathrm{M})$ for 24 h, $48 \mathrm{~h}$, and $72 \mathrm{~h}$, respectively, was evaluated by CCK- 8 cell viability assay. The results were demonstrated that EVO can obviously decrease the viability of BGC-823 and SGC-7901 cells, with the increase of EVO concentration during the treatment time, compared with the control group. And it can inhibit the proliferative activity of BGC-823 and SGC-7901 cells in a dose- and time-dependent manner (Figure 2(a)). Similarly, the plate colony-formation assay showed that EVO can inhibit the colony formation of BGC-823 and SGC-7901 cells in a dose-dependent manner (Figure 2(b)). Meanwhile, the $\mathrm{IC}_{50}$ values of EVO were 


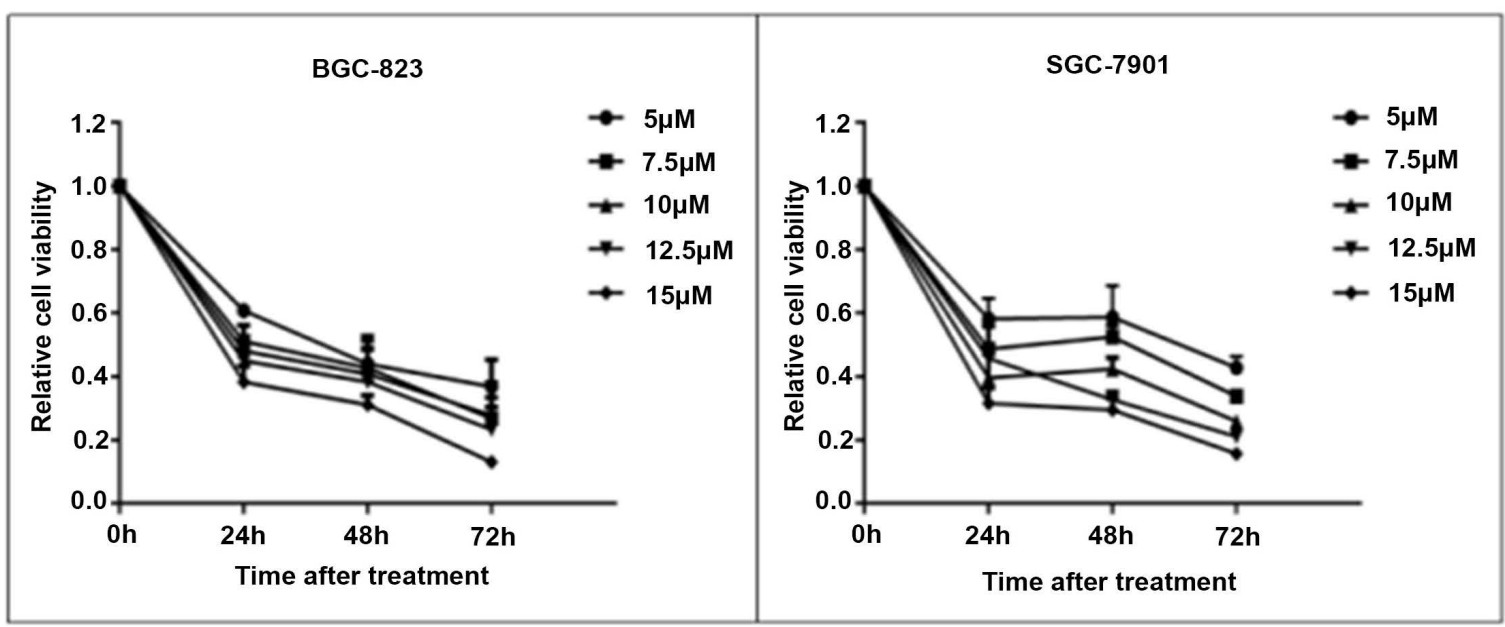

(a)

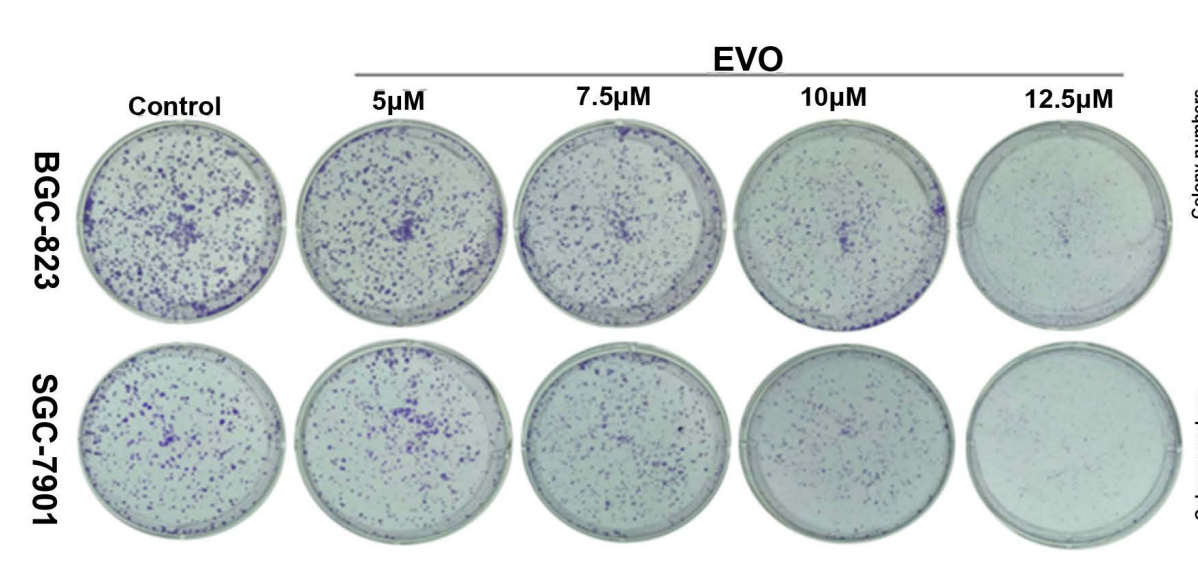

(b)
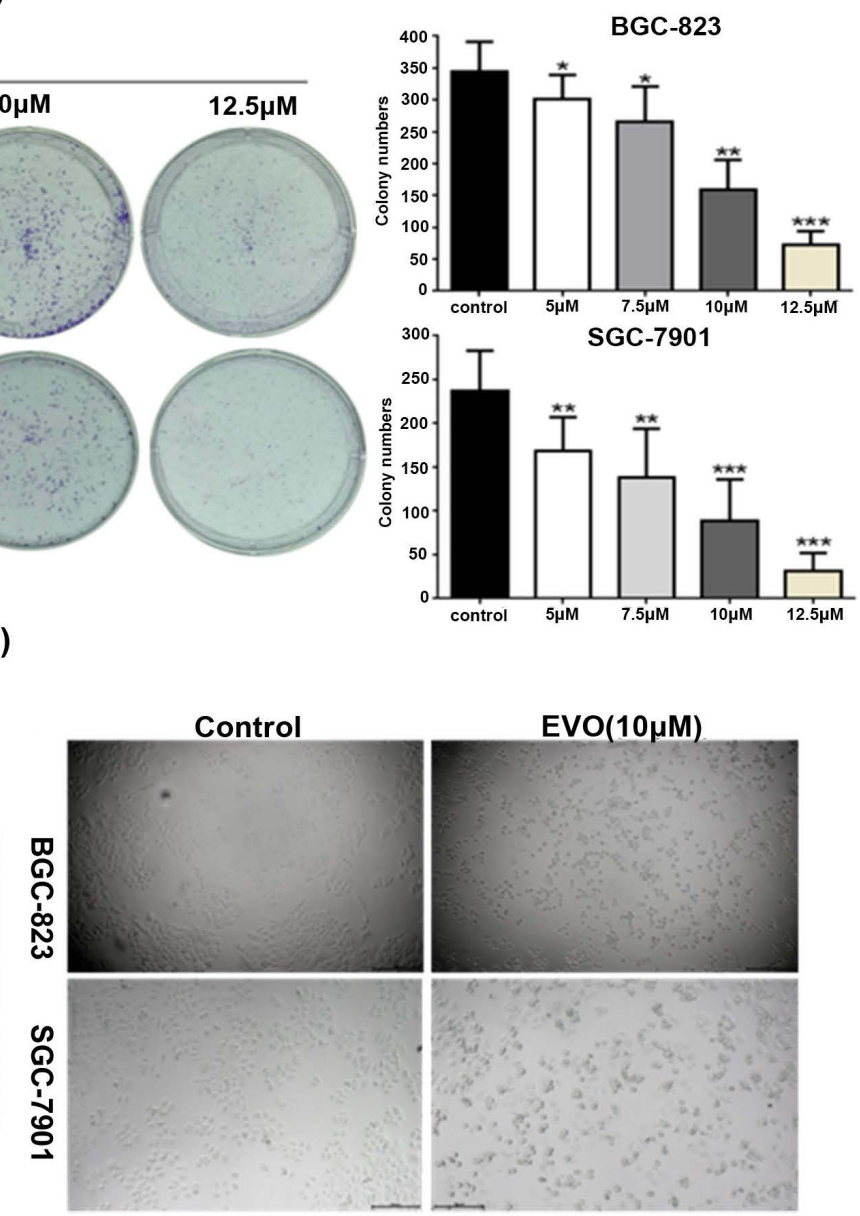

(c)

(d)

Figure 2. The effects of EVO on cell proliferation in gastric cancer cell lines BGC-823 and SGC-7901 cells. (a) Exponentially growing cells of BGC-823 and SGC-7901 cells were treated with EVO at the indicated concentrations $(0-15 \mu \mathrm{M})$ for 24 , 48 , and $72 \mathrm{~h}$; then, the percentages of viable cells were determined using CCK-8 assay. (b) The effect of EVO on the colony formation ability of BGC-823 and SGC-7901 cells. Data were shown as mean \pm SD from at least three independent experiments. ${ }^{\star} P<0.05$ and ${ }^{* \star} P<0.01$ vs. the Control group (culture medium only). (c) The $\mathrm{IC}_{50}$ value of EVO for BGC-823 and SGC-7901 cells. (d) The morphological changes of BGC-823 and SGC-7901 cells which treated with EVO $(10 \mu \mathrm{M})$ for 24 h were observed under the inverted microscope. 
respectively calculated by Graph-pad Prism7.0 software. The $\mathrm{IC}_{50}$ values of EVO were respectively $10.01 \mu \mathrm{M}$ and $9.73 \mu \mathrm{M}$ in BGC-823 and SGC-7901 cells after intervenion for $24 \mathrm{~h}$ (Figure 2(c)), so the follow-up experiments were used 10 $\mu \mathrm{M}$ as the working concentration. The microscopic observation was shown that, the cell bodies were not reduced, rounded and shrunk, even separated from each other, but also there were a small amount of particulate matter appeared and more cell debris in the culture solution after $24 \mathrm{~h}$, compared with the control group (Figure 2(d)). The results indicated that EVO has a better anti-gastric cancer activity.

\subsection{EVO Induces Gastric Cancer Cell Cycle Arrest at the G2/M Checkpoint}

We have verified that uncontrolled cell mitosis represents one of the hallmarks of cancer. Thus, we used the PI staining to inspect the effects of EVO on the cell cycle distrution upon BGC-823 and SGC-7901 cells by FCM. Luckly, cell cycle analysis revealed that the proportion of gastric cancer in G2/M phase was significantly increased after treatment for $24 \mathrm{~h}$. Specifically, after all cells were treated with $10 \mu \mathrm{M}$ EVO for $24 \mathrm{~h}$, the G0/G1 checkpoint ratio of BGC-823 and SGC-7901 cells were respectively decreased to $8.57 \% \pm 2.83 \%(\mathrm{t}=10.681, P<$ $0.001)$ and $23.11 \% \pm 4.84 \%(\mathrm{t}=5.376, P<0.01)$; the S-phase ratio were respectively rose up to $19.31 \% \pm 4.34 \%(\mathrm{t}=2.121, P<0.05)$ and $16.24 \% \pm 10.23 \%(\mathrm{t}=$ $-0.196, P>0.05)$; the cell cycle ratio in $\mathrm{G} 2 / \mathrm{M}$ checkpoint were increased to $54.13 \% \pm 6.81 \%(\mathrm{t}=-11.552, P<0.001)$ and $47.93 \% \pm 9.18 \%(\mathrm{t}=-10.776, P<$ 0.001), compared with the control group (Figure 3(a) and Figure 3(b)). Thus, EVO mainly induces gastric cancer cell cycle impeded at the G2/M checkpoint.

\subsection{EVO Reinforces the Apoptosis of Gastric Cancer Cells}

To determine if EVO could synergistically aggravate the apoptosis of gastric cancer cells, Annexin V-FITC/PI staining and FCM method were applied to detect the apoptotic events. After treatment with EVO $(10 \mu \mathrm{M})$ for $24 \mathrm{~h}$, the total apoptotic percentages were respectively $18.93 \% \pm 5.78 \%(\mathrm{t}=-12.728, P<0.001)$ and $17.24 \% \pm 5.07 \%(\mathrm{t}=-12.956, P<0.001)$, much higher than the $4.88 \% \pm$ $1.96 \%$ and $3.74 \% \pm 2.49 \%$ of the control group. Among them, EVO obviously induced the late apoptosis of cells, the apoptotic percentages were $16.13 \% \pm$ 4.53\% ( $\mathrm{t}=-10.844, P<0.001)$ and $10.87 \% \pm 5.67 \%(\mathrm{t}=-8.854, P<0.01)$, respectively, in EVO-treated BGC-823 and SGC-7901 cells (Figure 4(a) and Figure 4(b)). Together, the findings indicated that EVO inhibits the malignant proliferation of gastric cancer cells by inducing apoptosis.

\subsection{EVO Mediates the Activity of Apoptosis-Related Proteins and Cell Cycle-Related Proteins in Gastric Cancer Cells}

Based on the above results, we found that the mechanism of EVO inhibiting the proliferation of gastric cancer cells may be that EVO can block the development of cell cycle and induce apoptosis. Moreover, we detected the level of p 53 signaling and apoptosis-related proteins as well as caspases activation which were 


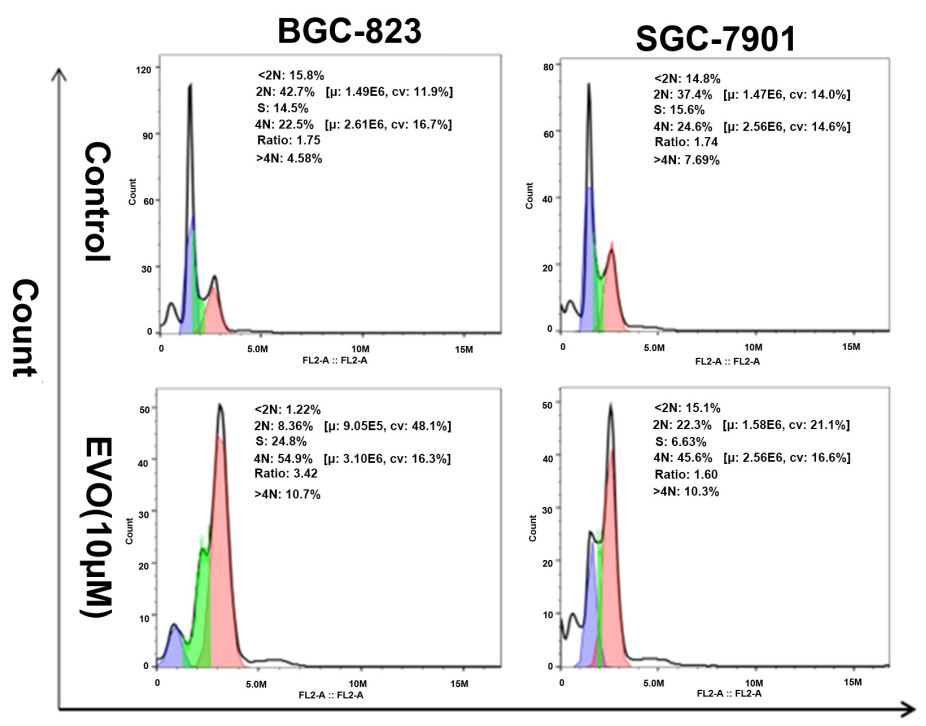

Propidium lodide-A

(a)
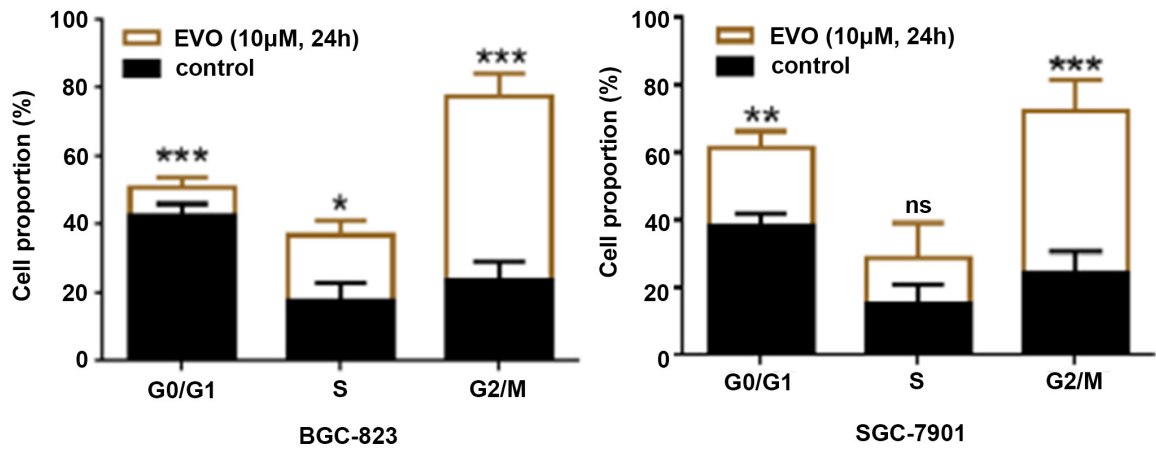

(b)

Figure 3. EVO induced gastric cancer cell cycle arrest at the G2/M phase. The length of each cell cycle phase was calculated and compared from three independent experiments. ${ }^{\star} P<0.05,{ }^{* *} P<0.01,{ }^{* *} P<0.001$ vs. the Control group.

examined by western-blot analysis. After treatment with EVO $(10 \mu \mathrm{M})$ at different points in time $(0,3,6,9,12,24 \mathrm{~h})$, the results showed that the expression levels of p53, cleaved-caspase-3, cleaved-caspase-8, cleaved-caspase-9 and cleaved-PARP-1 were significantly up-regulated, but the expression level of $\mathrm{cdc} 25 \mathrm{c}$ was marketably reduced, in the EVO-treated BGC-823 and SGC-7901 cells in a time-dependent manner compared with their control groups (Figure 5(a) and Figure 5(b)). Therefore, we concluded that EVO can induce gastric cancer cells apoptosis by regulating the activity caspases pathways, and accelerate cell cycle arrested at the G2/M checkpoint by changing the expression levels of p53 and cdc25c.

\section{Conclusions}

Evodiamine, extracted from dried roots and ripe fruits of Evodia rutaecarpa, has been demonstrated to exhibit various anticancer activities in a variety of tumor treatments. In this study, we assessed the anti-tumor effect of EVO and found 


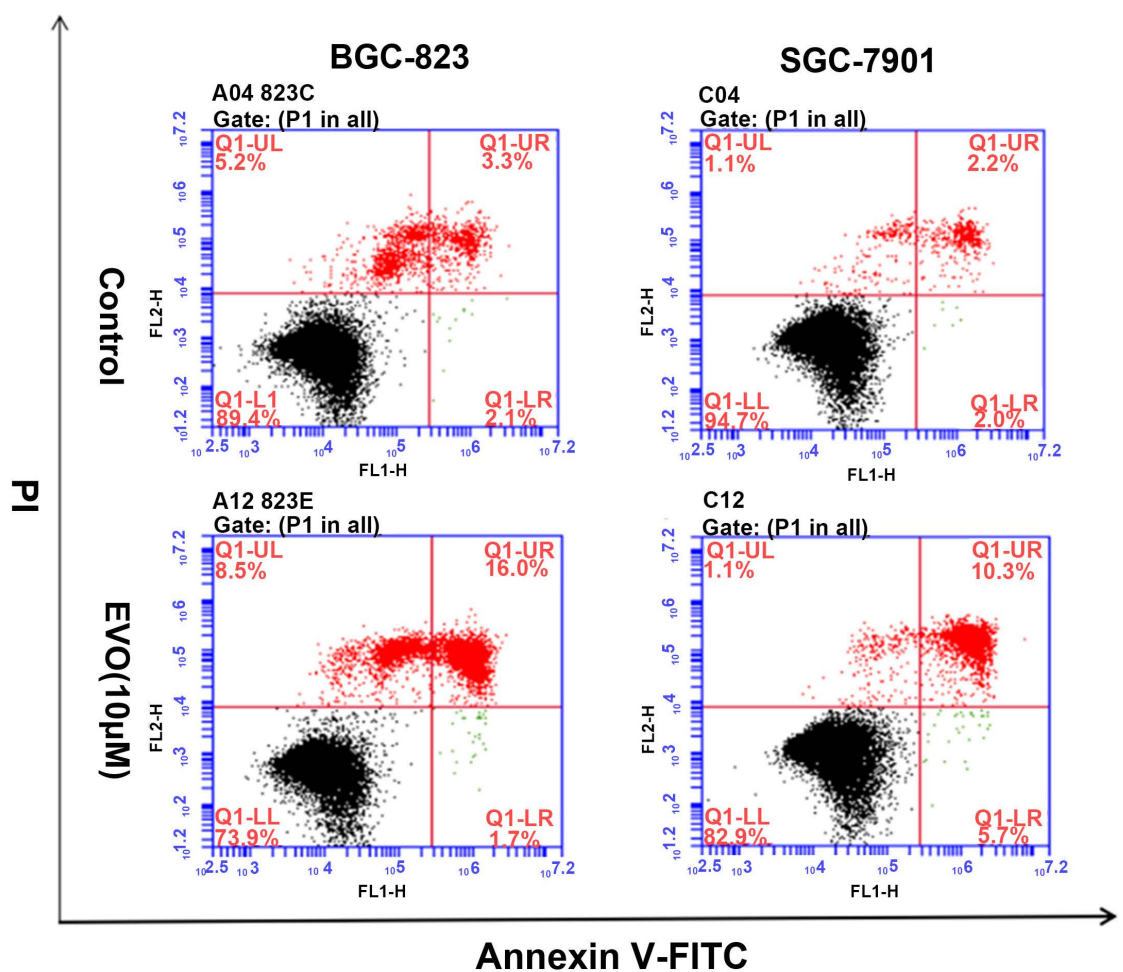

Annexin V-FITC
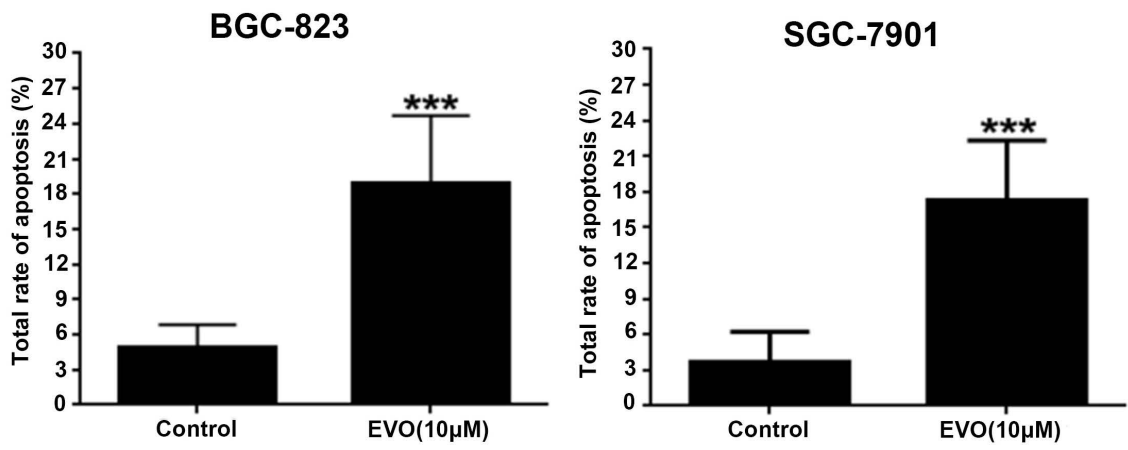

(b)

Figure 4. Apoptosis-induced effect of EVO was evaluated by FCM in BGC-823 and SGC-7901 cells, with Annexin V-FITC/PI staining. The apoptotic percentages from three independent experiments were analyzed and compared.

that it significantly inhibited the proliferation of BGC-823 and SGC-7901 cells by inducing cell cycle arrest at G2/M phase and cell apoptosis in a dose- and time-dependent manner.

Based on these preliminary observations, the molecular mechanisms underlying the anti-carcinogenic effects of EVO were further evaluated in gastric cancer cells. Abnormal cell cycle progression is the core link of malignant proliferation of tumor cells [14], so the process of regulating cell cycle is one of the effective ways to prevent abnormal proliferation of tumor cells. After the eukaryotic cells successfully passed the G1/S checkpoint, the periodic protein CyclinB1 began to accumulate and form a complex with CDC2 (CDK1) to propel the cells into the $M$ phase [15]. The periodic protein $c d c 25 c$ is very important to participate in the 


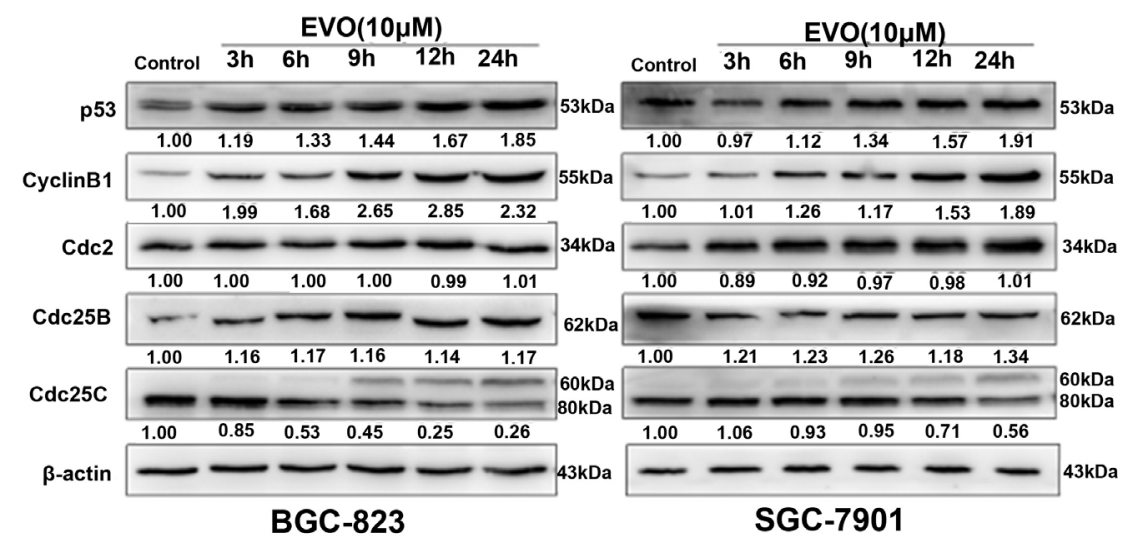

(a)
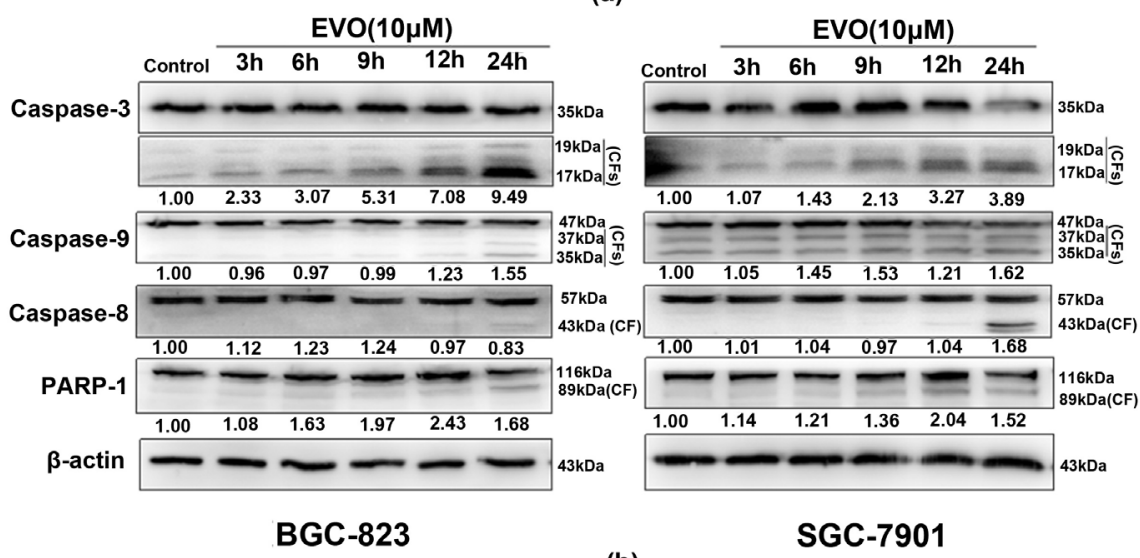

(b)

Figure 5. EVO suppressed the activity of p 53 signaling and caspases pathways in gastric cancer cells. BGC-823 and SGC-7901 cells were cultured in T25 flask and treated with EVO $(10 \mu \mathrm{M})$ at different points in time $(0,3,6,9,12,24 \mathrm{~h})$, then the expression of the indicated factors was examined by Western blot analysis. $\beta$-actin was used as the loading control. The densitometry analysis of every factor was performed, normalized with the corresponding $\beta$-actin content.

activation of CDC2, which can inhibit the activation of the CDC2/CyclinB1 complexes, inducing cancer cell cycle arrest at the G2/M checkpoint [16] [17]. At the same time, the expression of $c d c 25 \mathrm{c}$ is regulated by cell cycle inhibition protein p53. It can combine with cdc25c promoter to inhibit its transcription and maintain the smooth operation of cell cycle [18] [19]. Similarly, the results have shown that EVO can increase the expression of $\mathrm{p} 53$ and reduce the expression of cdc25c in BGC-823 and SGC-7901 cells after treatment for $24 \mathrm{~h}$.

On the other way, apoptosis is the autonomous and procedural death process of cells regulated by genes, in which caspases pathways and $\mathrm{p} 53$ play an important role in regulation of cell death [20] [21]. The results show that mitochondrial membrane potential change, death receptor pathway activation and others can cause caspases signal cascade activation to induce and amplify the effect of apoptosis cell [22] [23]. Caspase-3, as the most important effect factor of apoptosis, can induce the activation of shear death substrate PARP-1 [24] [25]. Importantly, our research also finds that EVO can raise the expression of cleaved 
caspase-3, cleaved caspase-8, cleaved caspase-9 and cleaved PARP-1 in BGC-823 and SGC-7901 cells, treated with EVO at different time, thus having prompted the activity of caspases pathways, which induces gastric cancer cells apoptosis.

Above all, EVO may induce gastric cancer cell arrest at G2/M checkpoint by promoting the expression of cell cycle inhibitor p53 and raising p53 expression and reducing the expression of cell cycle-promoting protein $\mathrm{Cdc} 25 \mathrm{C}$, as well as prompting the activity of caspases pathways to induce the apoptosis of gastric cancer cells. It provides new thoughts for our future research in which EVO is a new potential anticarcinogen for treatment of gastric cancer.

\section{Conflicts of Interest}

The authors declare no conflicts of interest regarding the publication of this paper.

\section{References}

[1] Ferlay, J., Soerjomataram, I., Dikshit, R., et al. (2015) Cancer Incidence and Mortality Worldwide: Sources, Methods and Major Patterns in GLOBOCAN 2012. International Journal of Cancer, 136, E359-E386. https://doi.org/10.1002/ijc.29210

[2] Chen, W.Q., Zheng, R.S., Peter, D., et al. (2016) Cancer Statistics in China, 2015. CA: A Cancer Journal for Clinicians, 2, 115-132. https://doi.org/10.3322/caac.21338

[3] Mihmanli, M., Ilhan, E., Idiz, U.O., et al. (2016) Recent Developments and Innovations in Gastric Cancer. World Journal of Gastroenterology, 22, 4307-4320. https://doi.org/10.3748/wjg.v22.i17.4307

[4] Feng, Y., Wu, C.Y. and Li, J. (2017) Research Progress on the Advantages and Possible Mechanisms of Traditional Chinese Medicine in the Treatment of Gastric Cancer. Liaoning Journal of Traditional Chinese Medicine, 44, 200-203.

[5] Zhang, Q.R., Zhou, Z.Y., Pan, Z.H., et al. (2018) Evodiamine Inhibits the Growth of Huh7 Cells and Enhances the Sensitivity of Cells to TRAIL. Chinese Journal of Pathophysiology, 34, 212-217.

[6] Yang, F., Shi, L., Liang, T., et al. (2017) Anti-Tumor Effect of Evodiamine by Inducing Akt-Mediated Apoptosis in Hepatocellular Carcinoma. Biochemical and Biophysical Research Communications, 485, 54-61. https://doi.org/10.1016/j.bbrc.2017.02.017

[7] Han, S., Woo, J.K., Jung, Y., et al. (2016) Evodiamine Selectively Targets Cancer Stem-Like Cells through the p53-p21-Rb Pathway. Biochemical and Biophysical Research Communications, 469, 1153-1158. https://doi.org/10.1016/j.bbrc.2015.12.066

[8] Huang, J., Chen, Z.H., Ren, C.M., et al. (2015) Antiproliferation Effect of Evodiamine in Human Colon Cancer Cells Is Associated with IGF-1/HIF-1 $\alpha$ Downregulation. Oncology Reports, 34, 3203-3211. https://doi.org/10.3892/or.2015.4309

[9] Mohan, V., Agarwal, R. and Singh, R.P. (2016) A Novel Alkaloid, Evodiamine Causes Nuclear Localization of Cytochrome-c and Induces Apoptosis Independent of p53 in Human Lung Cancer cells. Biochemical and Biophysical Research Communications, 477, 1065-1071. https://doi.org/10.1016/j.bbrc.2016.07.037

[10] Zhang, Y., Zhang, Q.H., Wu, L.J., et al. (2004) Cell Cycle Arrest in the Induction of Apoptosis in Mouse Fibrosarcoma L929 Cells. Chinese Journal of Integrated Traditional and Western Medicine, 24, 169-172. 
[11] Bai, X., Meng, H., Ma, L., et al. (2015) Inhibitory Effects of Evodiamine on Human Osteosarcoma Cell Proliferation and Apoptosis. Oncology Letters, 9, 801-805. https://doi.org/10.3892/ol.2014.2791

[12] Zhang, Z.X., Jiang, M.L., Wang, X.H., et al. (2014) Advances in Pharmacological Research of Evodiamine. Progress in Modern Biomedicine, 14, 4189-4191.

[13] Tian, X.L., Zhang, W. and Wang, X.L. (2011) Study on the Effect of Evodiamine on Human Gastric Adenocarcinoma Cell Line SGC-7901. Journal of Beijing University of Traditional Chinese Medicine, 34, 115-118.

[14] Evan, G.I. and Vousden, K.H. (2001) Proliferation, Cell Cycle and Apoptosis in Cancer. Nature, 411, 342-348. https://doi.org/10.1038/35077213

[15] Sanchez, I. and Dynlacht, B.D. (2005) New Insights into Cyclins, CDKs, and Cell Cycle Control. Seminars in Cell and Developmental Biology, 16, 311-321. https://doi.org/10.1016/j.semcdb.2005.02.007

[16] Peter, M., Le Peuch, C., Labbé, J.C., et al. (2002) Initial Activation of Cyclin-B1-cdc2 Kinase Requires Phosphorylation of Cyclin B1. EMBO Reports, 3, 551-556. https://doi.org/10.1093/embo-reports/kvf111

[17] Chien, C.C., Wu, M.S., Shen, S.C., et al. (2014) Activation of JNK Contributes to Evodiamine-Induced Apoptosis and G2/M Arrest in Human Colorectal Carcinoma Cells: A Structure-Activity Study of Evodiamine. PLoS ONE, 9, e99729. https://doi.org/10.1371/journal.pone.0099729

[18] Lu, X., Liu, D.A. And Xu, Y. (2013) The Gain of Function of p53 Cancer Mutant in Promoting Mammary Tumorigenesis. Oncogene, 32, 2900-2906. https://doi.org/10.1038/onc.2012.299

[19] Yin, X., Zhang, R., Feng, C., et al. (2014) Diallyl Disulfide Induces G2/M Arrest and Promotes Apoptosis through the p53/p21 and MEK-ERK Pathways in Human Esophageal Squamous Cell Carcinoma. Oncology Reports, 32, 1748-1756. https://doi.org/10.3892/or.2014.3361

[20] Godefroy, N., Lemaire, C., Renaud, F., et al. (2004) P53 Can Promote Mitochondriaand Caspase-Independent Apoptosis. Cell Death \& Differentiation, 11, 785-787. https://doi.org/10.1038/sj.cdd.4401398

[21] Wawryk-Gawda, E., Chylińska-Wrzos, P., Lis-Sochocka, M., et al. (2014) P53 Protein in Proliferation, Repair and Apoptosis of Cells. Protoplasma, 251, 525-533. https://doi.org/10.1007/s00709-013-0548-1

[22] St. Clair, S., Giono, L., Varmeh-Ziaie, S., et al. (2004) DNA Damage-Induced Downregulation of Cdc25C Is Mediated by p53 via Two Independent Mechanisms: One Involves Direct Binding to the cdc25C Promoter. Molecular Cell, 16, 725-736. https://doi.org/10.1016/j.molcel.2004.11.002

[23] Fu, Z., Han, X., Du, J., et al. (2018) Euphorbialunulata Extract Acts on Multidrug Resistant Gastric Cancer Cells to Inhibit Cell Proliferation, Migration and Invasion, Arrest Cell Cycle Progression, and Induce Apoptosis. Journal of Ethnopharmacolo$g y, 212,8-17$. https://doi.org/10.1016/j.jep.2017.08.014

[24] Zhang, X. and Song, T. (2002) Study on Caspase-3 and Apoptosis. Medical Review, 8, 621-623.

[25] Xu, Y., Gao, C.C., Pan, Z.G., et al. (2018) Irigenin Sensitizes TRAIL-Induced Apoptosis via Enhancing Pro-Apoptotic Molecules in Gastric Cancer Cells. Biochemical and Biophysical Research Communications, 496, 998-1005.

https://doi.org/10.1016/j.bbrc.2018.01.003 